\title{
Steady-State Analysis and Stability of Synchronous Reluctance Motors Considering Saturation Effects
}

\author{
Mohamed. N. Ibrahim, Student Member IEEE, Essam. M. Rashad, SMIEEE and Peter. Sergeant, Member IEEE
}

\begin{abstract}
This paper investigates the influence of the magnetic saturation on the performance of a Synchronous Reluctance Motor (SynRM) at steady-state. In addition, the stability limits for the SynRM are studied using a suggested more accurate method. The saturation and cross-saturation effects on both direct $(d)$ and quadrature $(q)$ axis flux linkages are considered. A Finite Element Method (FEM) is used to obtain an accurate representation for the $d q$-axis flux linkages relations. In order to reduce the calculation time of the finite element analysis, a look-up table (LUT) for the $d q$-axis flux linkages is generated based on the FEM to be used for simulating the SynRM characteristics. It is found that the magnetic saturation in the adopted motor results in an enlarged region of stable operation of the SynRM by about 200 $\%$ compared with the unsaturated case. The results show the importance of including the saturation factors on the performance of the SynRM and its stability limits. Hence, the magnetic saturation effect will not only reflect on the stability of the motor but also on the whole drive system.
\end{abstract}

Index Terms - FEM, Magnetic Saturation, Stability Limits, Synchronous Reluctance Motor.

\section{NOMENClAtURE}

$I_{d}, I_{q} \quad$ Steady-state values of direct and quadrature component of stator current receptively, A

$\lambda_{d}, \lambda_{q} \quad$ Direct and quadrature axis flux linkage of SynRM respectively, V.sec

$L_{d}, L_{q} \quad$ Direct and quadrature axis stator inductance of SynRM respectively, $\mathrm{H}$

$P \quad$ Number of pole pairs

$R_{S} \quad$ Stator resistance of SynRM, $\Omega$

$T_{e} \quad$ Electromagnetic torque of the motor, N.m

The authors acknowledge the Egyptian Ministry of Higher Education (Cultural Affairs and Missions Sector) and Special Research Fund of Ghent University (BOF) for the financial support during this work.

M. N. Ibrahim is with the Department of Electrical Energy, Systems and Automation, Ghent University, Ghent B-9000, Belgium, the Department of Industrial Technology \& Construction, Ghent University, B-9000 Ghent, Belgium, and Electrical Engineering Department, Kafrelshiekh University, Kafrelshiekh, Egypt (e-mail: m.nabil@eng.kfs.edu.eg).

E. M. Rashad is with the Department of Electrical Power and Machines, Tanta University, Tanta, Egypt (e-mail: emrashad@feng.tanta.edu.eg).

P. Sergeant is with the Department of Electrical Energy, Systems and Automation, Ghent University, Ghent B-9000, Belgium and the Department of Industrial Technology \& Construction, Ghent University, B-9000 Ghent, Belgium (e-mail: peter.sergeant@ugent.be).

\author{
$V_{d}, V_{q} \quad$ Steady-state values of direct and quadrature \\ component of stator voltage respectively, $\mathrm{V}$ \\ $V_{m} \quad$ Maximum input voltage of the motor, $\mathrm{V}$ \\ $I_{m} \quad$ Maximum input current of the motor, A \\ $\delta, \alpha \quad$ Load angle and current angle, rad \\ $\omega_{r}, \omega_{s} \quad$ Motor and synchronous speed, $\mathrm{rad} / \mathrm{s}$ \\ $\theta_{r} \quad$ Rotor position, rad \\ $P F \quad$ Motor power factor
}

\section{INTRODUCTION}

$\mathrm{S}$ ynchronous Reluctance Motors (SynRMs) have received more attention for many applications, thanks to their rugged construction and the absence of rareearth magnets [1]. They have many attractive features compared with other types of motors as there are no cage, windings and magnets on the rotor. The torque per ampere is acceptable and they can withstand high temperatures as well as high centrifugal forces [2]. Moreover, the control system is similar to that of induction motor drives and they are suitable for super high speed applications in machine tools and molecular pumps $[2,3]$.

The performance of a SynRM depends mainly on direct and quadrature axis inductances $\left(L_{d}, L_{q}\right)$ which are affected by the rotor geometry. In addition, the $d q$-axis inductances of the SynRM with a flux-barrier rotor type vary with both $d q$ currents, due to sharing the same flux path on the rotor core. Also the position of the rotor with respect to the stator has an effect on the SynRM inductances. The $d q$-axis inductances do not only depend on the self-currents but also on the mutual ones. This dependency is called the crosssaturation effect. Therefore, a model considering the saturation effect is necessary for an accurate representation for the SynRM control and efficiency optimization [4, 5].

Several papers have been focused on the saturation and cross-saturation effects on the SynRM performance and control. Different models have been proposed to take into account the effect of the magnetic saturation for electrical machines [5-10].

In [5], the impact of cross-saturation in SynRM of transverse-laminated type is investigated with a mixed theoretical and experimental approach considering assumptions in the measuring of the $d q$-axis flux linkages relations. The stability limits of interior permanent magnet (IPM) motors have been investigated in [7] when considering different effects of magnetic saturation and it has been proved the importance of including the magnetic 
saturation on the performance IPM motors. In [8], a magnetic saturation effects on the control of a SynRM was studied based on a single saturation factor with measurable results assuming that the $d q$-axis inductances saturate to the same level at all the operating conditions. In [9], a saturation modelling in D-Q axis models of salient pole synchronous machines was proposed based on generalized forms tacking into account a single saturation factor with the same saturation level in both $d q$-axis inductances. The effect of a different level of saturation of the magnetic rotor path, comparing the performance of some SynRMs has been investigated on [10].

This paper analyses deeply the influence of the magnetic saturation on steady-state for the SynRM performance and its stability limits. A Finite Element Method (FEM) is used to obtain an accurate representation for the $d q$-axis flux linkages relations. To reduce the calculation time, a Lookup table (LUT) based on the FEM is generated to be used in the simulation of the motor behaviour at steady-state condition.

This paper is organized as follows. Section III presents the modelling of the SynRM at steady-state conditions considering the magnetic saturation effect. Afterwards, section IV deals with the steady-state analysis for the SynRM performance and its stability limits.

\section{SYNRM MODELLING}

\section{A. Nonlinear dq model of SynRM}

In order to eliminate the time-varying inductances in the voltage equations, the SynRM was represented in the $d q$ axis reference frame. This frame is fixed on the rotor, which rotates at $\omega_{\mathrm{r}}[3,11,12]$.

The steady-state $d q$-axis voltage equations can be written as:

$$
\begin{aligned}
& V_{d}=R_{s} I_{d}-\omega_{r} P \lambda_{q}\left(I_{d}, I_{q}\right) \\
& V_{q}=R_{s} I_{q}+\omega_{r} P \lambda_{d}\left(I_{d}, I_{q}\right)
\end{aligned}
$$

where

$$
\begin{aligned}
& V_{d}=-V_{m} \sin (\delta) \\
& V_{q}=V_{m} \cos (\delta) \\
& \lambda_{d}\left(I_{d}, I_{q}\right)=L_{d}\left(I_{d}, I_{q}\right) I_{d} \\
& \lambda_{q}\left(I_{d}, I_{q}\right)=L_{q}\left(I_{d}, I_{q}\right) I_{q}
\end{aligned}
$$

The steady-state electromagnetic torque is given by:

$$
T_{e}=\frac{3}{2} P\left(\lambda_{d}\left(I_{d}, I_{q}\right) I_{q}-\lambda_{q}\left(I_{d}, I_{q}\right) I_{d}\right)
$$

The $d q$-axis currents can be expressed as a function of current angle $(\alpha)$.

$$
I_{d}=I_{m} \cos (\alpha), I_{q}=I_{m} \sin (\alpha)
$$

where $\alpha$ is the angle between the stator current space vector with respect to the $d$-axis of the motor as shown in Fig. 1 .

Neglecting the stator resistance $R_{s}$, the power factor (PF) of the SynRM can be expressed as a function of the saliency ratio $(K)[13]$ :

$$
P F=\frac{K-1}{\sqrt{K^{2} \frac{1}{\sin ^{2}(\alpha)}+\frac{1}{\cos ^{2}(\alpha)}}}
$$

where $K$ denotes saliency ratio $\left(L_{d} / L_{q}\right)$.

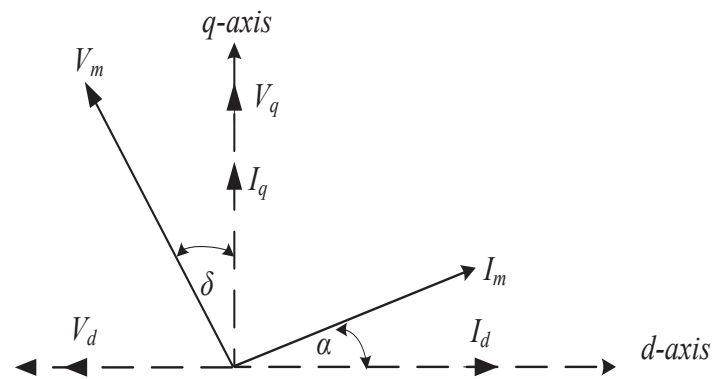

Fig. 1. Current and voltage diagrams

\section{B. Finite Element Method (FEM) for the SynRM}

A FEM is used to calculate the $d q$-axis flux linkages $\left(\lambda_{d}\left(I_{d}, I_{q}, \theta_{r}\right), \lambda_{q}\left(I_{d}, I_{q}, \theta_{r}\right)\right)$ of the SynRM. The FEM is supplied with different $I_{d}, I_{q}$ and $\theta_{r}$ for all possible combinations of variable stator currents from 0 to the rated value $\left(I_{m}\right)$ to obtain the $d q$-axis flux linkages relations for the SynRM. The number of nodes and elements of the FEM model are approximately 31238 and 56371 respectively at 50 rotor positions. The SynRM has four poles with symmetrical geometry so that it is sufficient to model only a quarter of the motor geometry. The parameters of the adopted motor are specified on table I (Appendix section).

Figure 2 shows the flux paths in a quarter of the utilized motor geometry using FEM.

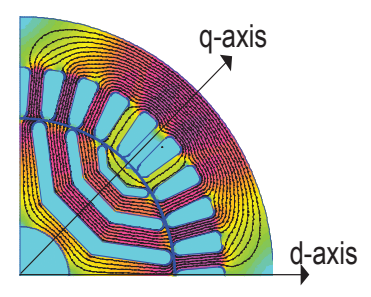

(a) $\theta_{r}=0^{\circ}$

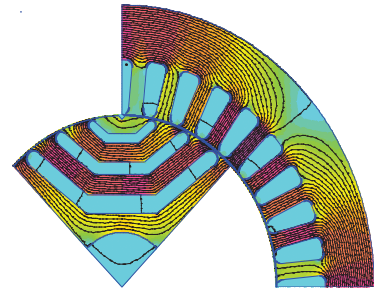

(b) $\theta_{r}=45^{\circ}$
Fig. 2. Flux paths for the adopted SynRM using FEM for a quarter geometry with different positions

To understand clearly the saturation and the cross saturation effects, a sample of the results for the $d q$-axis flux linkages with an averaging with respect to the position $\left(\theta_{r}\right)$ is considered. Figure 3 shows the variation of $I_{d}$ and $I_{q}$ with increasing the stator current of the SynRM up to the rated value $\left(I_{m}=30 \mathrm{~A}\right)$. The values of $I_{d}$ and $I_{q}$ which used to obtain the $d q$-axis flux linkages in the FEM calculations are remarked on Fig. 3. Figure 4 shows the variation of the $d$ axis flux linkage with $I_{d}$ for different stator current. It is obvious that the $d$-axis flux linkage changes linearly with $I_{d}$ till $I_{d}$ increases more than the half of the rated value (15A) 
and then becomes saturated. In fact, this saturation does not only depend on the value of $I_{d}$ but also on the rotor flux path geometry (Fig. 2). In addition, the effect of $I_{q}$ on the $d$-axis flux linkage is very small.

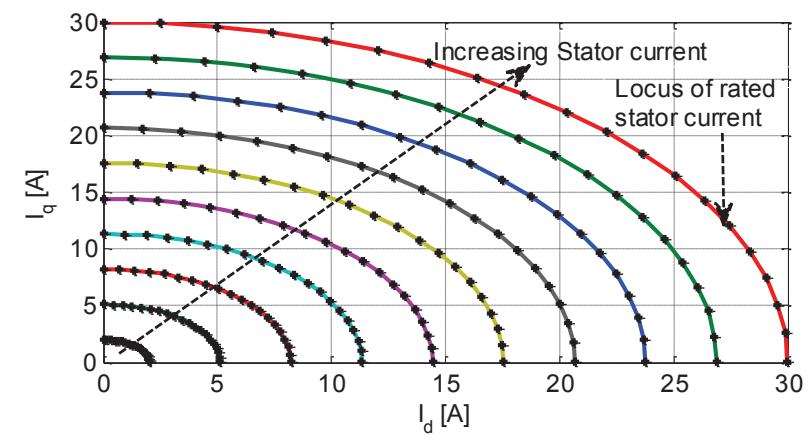

Fig. 3. $I_{d}$ versus $I_{q}$ at different stator currents

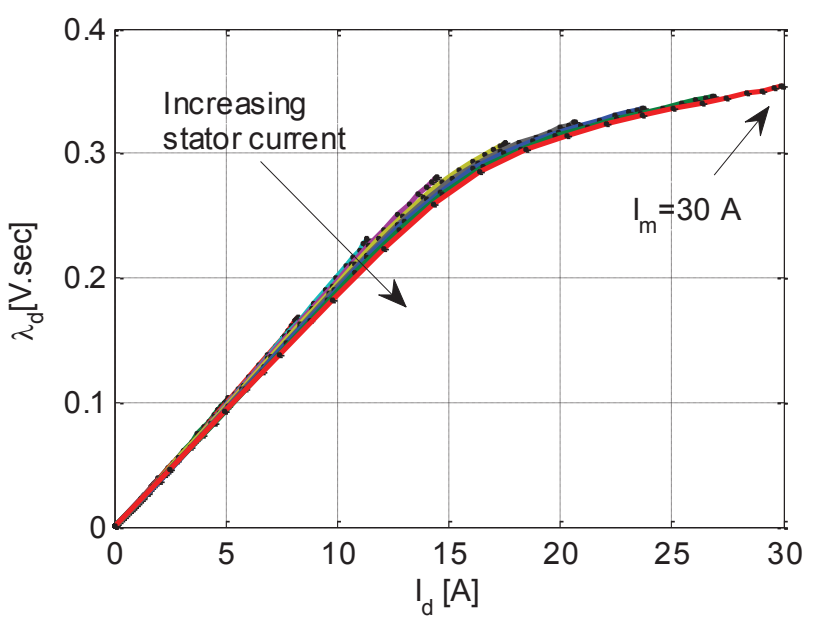

Fig. 4. $I_{d}$ versus $\lambda_{d}$ at different stator currents

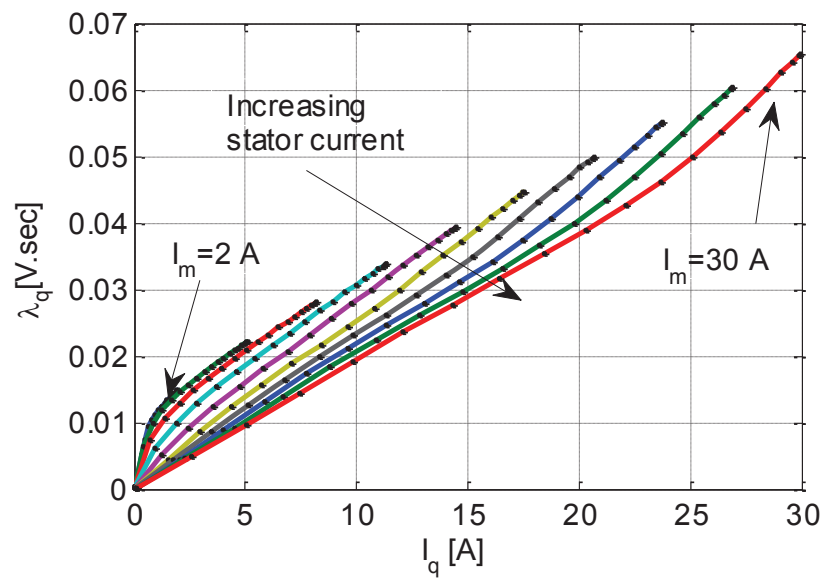

Fig. 5. $I_{q}$ versus $\lambda_{q}$ at different stator currents

Figure 5 shows the variation of the $q$-axis flux linkage with $I_{q}$ for different stator current. It can be seen that this variation is linear due to the high magnetic reluctance in the $q$-axis. Moreover, the cross-saturation has a high effect on the $q$-axis flux linkage compared with the $d$-axis flux linkage.
A Look-up table (LUT) is generated based on the calculated $d q$-axis flux linkages from the FEM. This LUT is used in the simulation program to simulate the accurate behaviour of the SynRM. Using the LUT, for any $I_{d}$ and $I_{q}$ the corresponding $d q$-axis flux linkages can be obtained.

\section{STEADY-STATE ANALYSIS FOR THE SYNRM}

In order to study the effect of the saturation on the performance of the SynRM and its stability limits at steadystate, nonlinear calculations for the adopted motor at the rated speed and voltage are done. Various characteristics for the SynRM performance at steady-state operation including and neglecting saturation are investigated based on two cases. The first case is to study the effect of different $q$-axis inductance values at one value of $d$-axis inductance on the SynRM behaviour compared with the saturated one. While the second case is to study the effect of different $d$-axis inductance values at one value for $q$-axis inductance compared with the saturated one.

\section{A) The effect of different q-axis inductance}

For the first case, it's considered one unsaturated (constant) value for $L_{d}=0.0185 \mathrm{H}$ with different unsaturated values for $L_{q}=0.005 \mathrm{H}, 0.003 \mathrm{H}$ and $0.002 \mathrm{H}$. On the one hand, the selection of $L_{d}=0.0185 \mathrm{H}$ is to represent approximately the average value of $d$-axis inductance in the linear region (neglecting saturation and cross-saturation effects) of the $d q$-axis flux linkages. On the other hand, the selection of the three different values for the $q$-axis inductance $\left(L_{q}=0.005 \mathrm{H}, 0.003 \mathrm{H}\right.$ and $\left.0.002 \mathrm{H}\right)$ is to represent approximately the average value of $q$-axis inductance in the linear, knee and saturation regions of the $d q$-axis flux linkages.

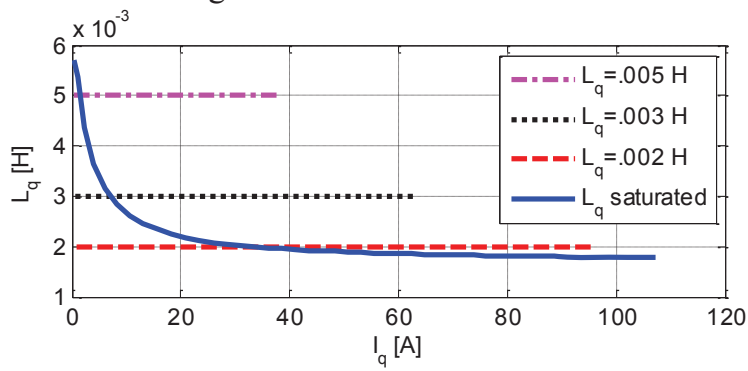

Fig. 6. $\mathrm{I}_{\mathrm{q}}-\mathrm{L}_{\mathrm{q}}$ characteristics for the adopted motor

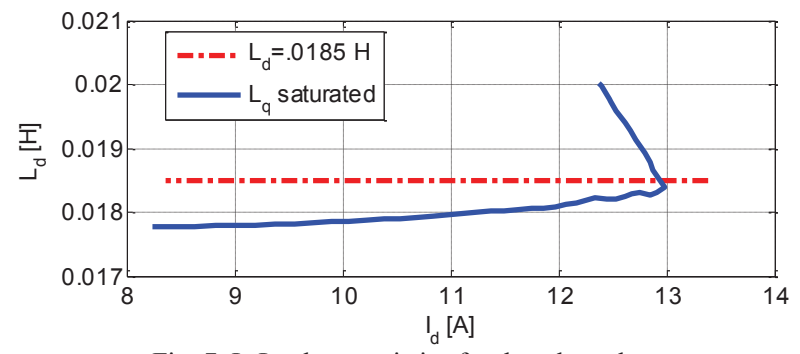

Fig. 7. $\mathrm{I}_{d}-\mathrm{L}_{d}$ characteristics for the adopted motor 
Figure 6 and 7 show $I_{q}-L_{q}$ and $I_{d}-L_{d}$ characteristics for saturated and unsaturated cases of the adopted motor.

Figure 8 and 9 show the variation of $I_{d}$ and $I_{q}$ with the load angle for different inductances with considering and neglecting the saturation effect. The variation of $I_{d}$ for different inductances is negligible due to the small change between the saturated and unsaturated values compared with a high variation on $I_{q}$. The $I_{q}$ increases with decreasing $L_{\mathrm{q}}$ where $I_{q}$ changes from $40 \mathrm{~A}$ with neglecting saturation effect and $L_{q}=0.005 \mathrm{H}$ to about $100 \mathrm{~A}$ when considering the magnetic saturation effect.

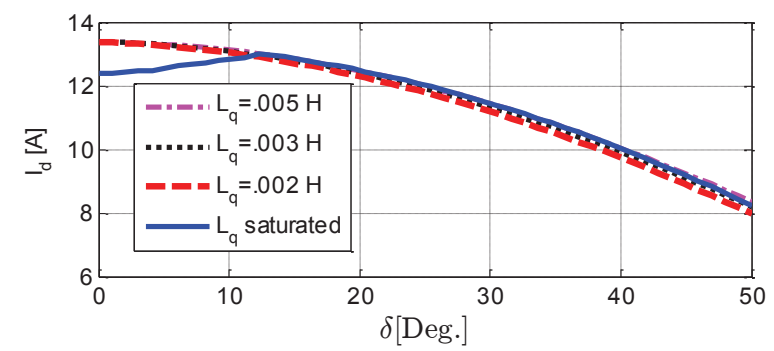

Fig. 8. Variation of $\delta$ with $\mathrm{I}_{\mathrm{d}}$ for different unsaturated q-axis inductance compared to saturated one.

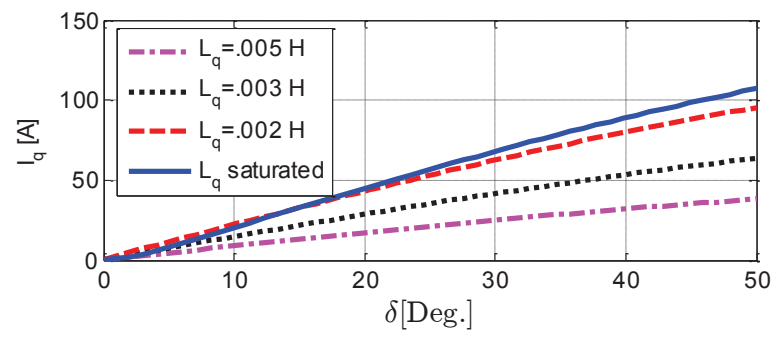

Fig. 9. Variation of $\delta$ with $I_{q}$ for different unsaturated q-axis inductance compared to saturated one.

Two extreme limiting values for the motor torque stability region can be shown in Fig. 10 from about $15 \mathrm{Nm}$ with neglecting saturation effect to about $43 \mathrm{Nm}$ when considering the magnetic saturation. This is due to the mainly dependence of the SynRM torque on the saliency ratio $\left(L_{d} / L_{q}\right)$. The motor torque increases with increasing the saliency ratio as seen from Fig. 10. The load angle is a negative value but it's drawn as a positive in the figures.

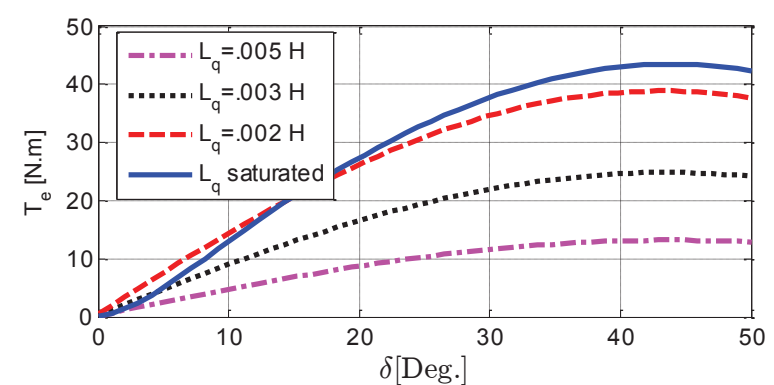

Fig. 10. Variation of $\delta$ with $\mathrm{T}_{\mathrm{e}}$ for different unsaturated q-axis inductance compared to saturated one.

Figure 11 shows the variation of the motor power factor with the load angle. The power factor of the SynRM depends on the motor output power and the saliency ratio $\left(L_{d} / L_{q}\right)$. It can be deduced that the motor operating point has a higher effect on the power factor than the variation of the inductances. The magnetic saturation leads almost to have a higher power factor for all load angle values compared with the unsaturated one.

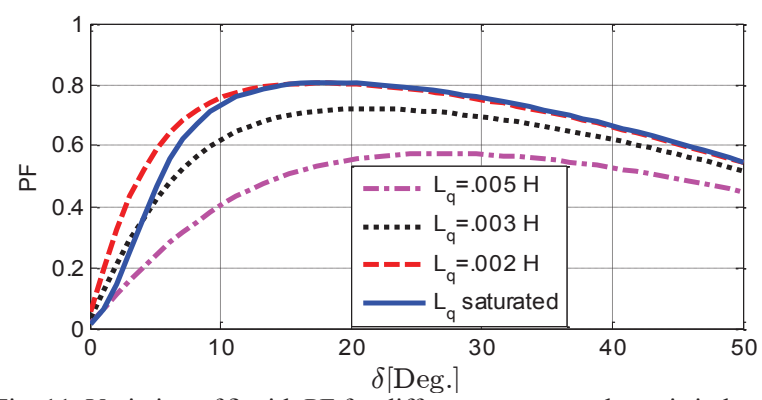

Fig. 11. Variation of $\delta$ with PF for different unsaturated q-axis inductance compared to saturated one.

\section{B) The effect of different d-axis inductance}

For the second case, it's included one unsaturated value for $L_{q}=0.003 \mathrm{H}$ and different unsaturated values for $L_{d}=0.012 \mathrm{H}, 0.016 \mathrm{H}$ and $0.0185 \mathrm{H}$. On the one hand, the selection of $L_{q}=0.003 \mathrm{H}$ is to represent approximately the average value of $q$-axis inductance in the linear region (neglecting saturation and cross-saturation effects) of the $d q$ - axis flux linkages. On the other hand, the selection of the three different values for the $d$-axis inductance $\left(L_{d}=0.0185 \mathrm{H}, 0.016 \mathrm{H}\right.$ and $0.012 \mathrm{H}$ ) is to represent approximately the average value of $d$-axis inductance in the linear, knee and saturation regions of the $d q$-axis flux linkages.

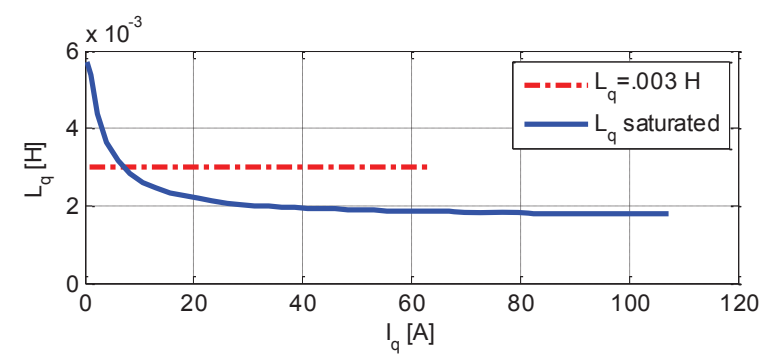

Fig. 12. $\mathrm{I}_{\mathrm{q}}-\mathrm{L}_{\mathrm{q}}$ characteristics for the adopted motor

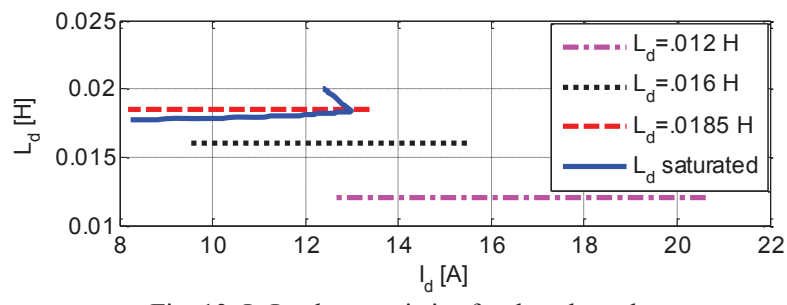

Fig. 13. $I_{d}-L_{d}$ characteristics for the adopted motor

Figure 12 and 13 show $I_{q}-L_{q}$ and $I_{d}-L_{d}$ characteristics of the adopted motor considering and neglecting the magnetic saturation effect. 
The variation of the load angle with $I_{q}$ and $I_{d}$ for different unsaturated $d$-axis inductance compared to saturated one can be shown in Figs. 14 and 15 respectively. Due to the same $q$-axis inductance the $I_{q}$ is the same for different $L_{d}$. There is a variation on the $I_{d}$ as a result of different $L_{d}$.

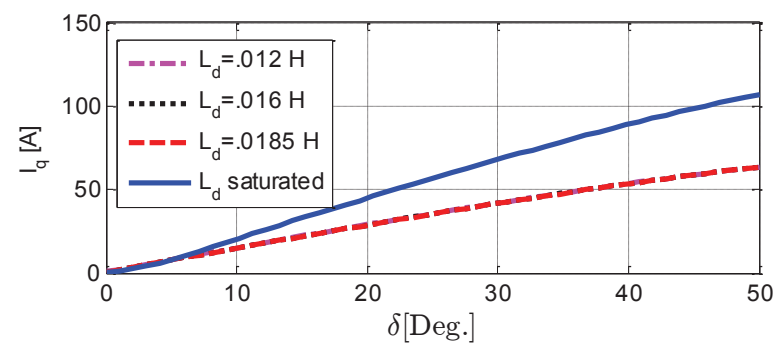

Fig. 14. Variation of $\delta$ with $\mathrm{I}_{\mathrm{q}}$ for different unsaturated d-axis inductance compared to saturated one.

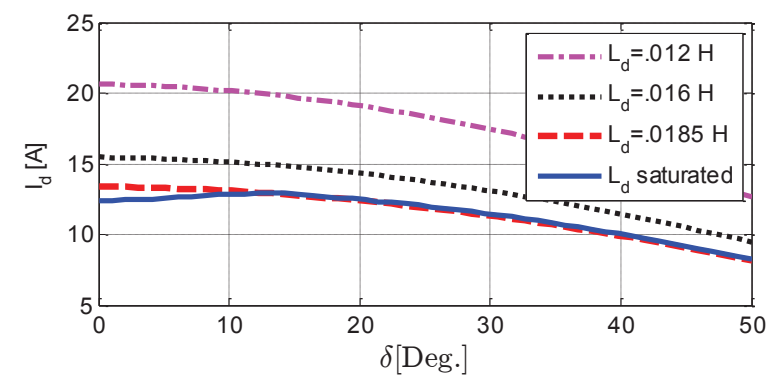

Fig. 15. Variation of $\delta$ with $\mathrm{I}_{\mathrm{d}}$ for different unsaturated d-axis inductance compared to saturated one.

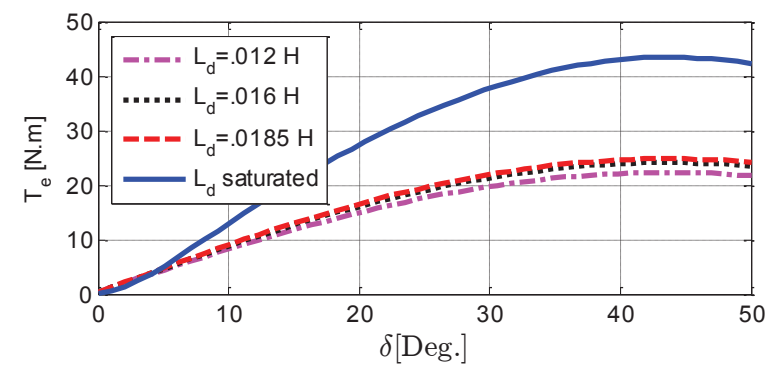

Fig. 16. Variation of $\delta$ with $\mathrm{T}_{\mathrm{e}}$ for different unsaturated d-axis inductance compared to saturated one.

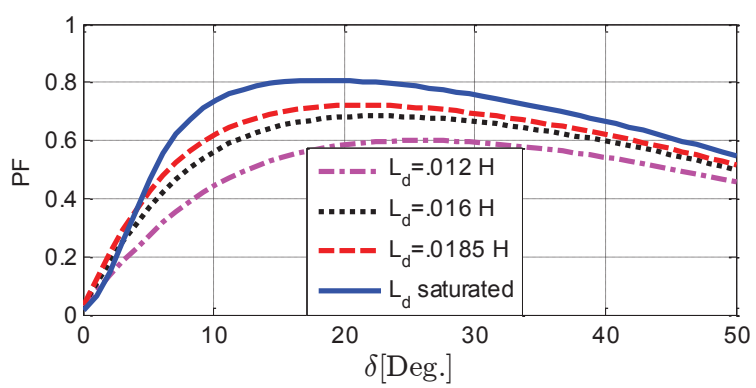

Fig. 17. Variation of $\delta$ with PF for different unsaturated d-axis inductance compared to saturated one.

Figure 16 describes the variation of the motor torque with the load angle at different unsaturated $d$-axis inductance compared with including the saturation effect. The motor stability region can be increased from about 25 N.m with the constant values for the $d q$-axis inductances to about 43 N.m with including the saturation effect. Moreover, it's obvious the lower effect on the performance and the stability region of the SynRM considering different $L_{d}$ compared with different $L_{q}$ (Figs. 6: 11). This is due to the $I_{\mathrm{d}}-L_{d}$ and $I_{q}-L_{\mathrm{q}}$ characteristics.

Figure 17 shows the variation of the motor power factor with the load angle at different unsaturated $d$-axis inductance compared with including the magnetic saturation effect.

\section{V.CONCLUSION}

This article has presented the influence of the magnetic saturation on the SynRM performance at steady-state. Moreover, the stability limits of operation for the adopted motor has been investigated. A FEM is used to obtain a more accurate relations for the $d q$ - axis flux linkages of the motor considering the saturation and the cross-saturation effects. In order to reduce the calculation time of the FEM, a look-up table (LUT) is generated based on the FEM calculation to be used on the simulation for the SynRM characteristics at steady. On the one hand, it's noted that the $d$-axis flux linkage varies linearly with $I_{d}$ at lower values for $I_{d}$ about half of the rated value and then becomes saturated with increasing $I_{d}$. On the other hand, $q$-axis flux linkage varies linearly with $I_{q}$. The effect of $I_{q}$ on the $d$-axis flux linkage is very small compared to the effect of $I_{d}$ on the $d$ axis. The variation on $q$-axis flux linkage has a great impact on the SynRM performance and its stability limits.

The magnetic saturation increases the stability region and the torque capability of the SynRM by about $200 \%$ compared with the unsaturated case.

Finally, the results show the importance of including the magnetic saturation on the modeling of the SynRM performance and its stability limits.

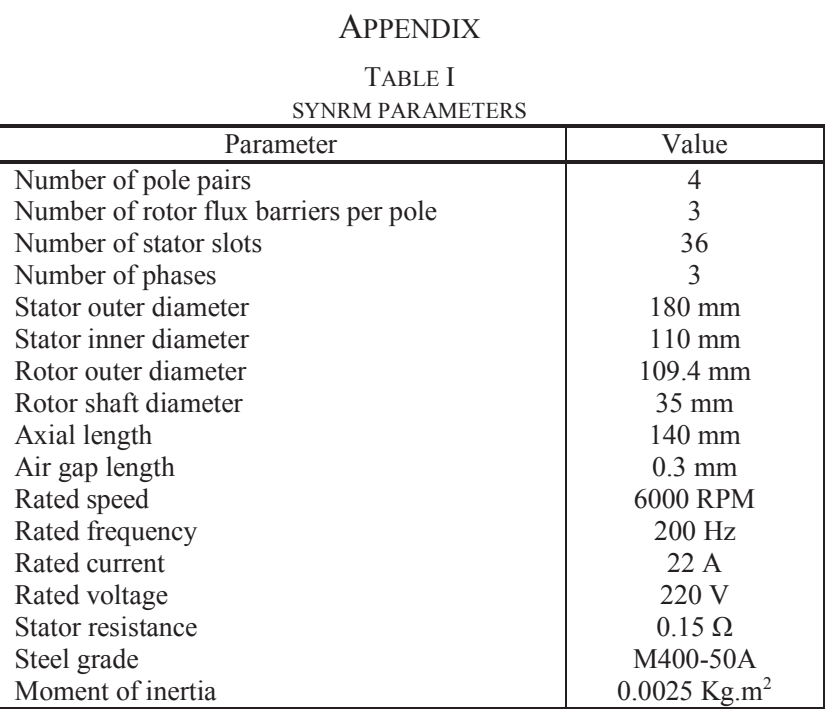




\section{REFERENCES}

[1] E. Daryabeigi, H. Abootorabi Zarchi, G. R. Arab Markadeh, J. Soltani, and F. Blaabjerg, "Online MTPA control approach for synchronous reluctance motor drives based on emotional controller," IEEE Trans. Power Electronic. vol. 30, no. 4, pp. 2157-2166, Apr. 2015.

[2] S. Taghavi, and P. Pillay, "A sizing methodology of the synchronous reluctance motor for traction applications," IEEE Jour. Eem. And Sel. Topics in Power Electronic. vol. 2 no. 2, pp. 329-340, Jun. 2014.

[3] M. Nabil, S. M. Allam and E. M. Rashad, "Performance improvement of a photovoltaic pumping system using a synchronous reluctance motor," Electric Power Components and Systems Journal, vol. 41, no. 4, pp. 474-464, Jan. 2013.

[4] Shu Yamamoto, Takahiro Ara, and Kouki Matsuse, "A Method to calculate transient characteristics of synchronous reluctance motors considering iron loss and cross-magnetic saturation," IEEE Trans. Ind. Appl., vol. 43, no. 1, pp. 47-56, Jan./Feb. 2007.

[5] A. Vagati, M. Pastorelli, F. Scapino, and G. Franceschini, "Impact of cross saturation in synchronous reluctance motors of the transverse laminated type," IEEE Trans. Ind. Appl., vol. 36, no. 4, pp. 10391046, Jul./Aug. 2000.

[6] Bojan Stumberger, Gorazd Stumberger, Drago Dolinar, Anton Hamler, and Mladen Trlep, "Evaluation of saturation and crossmagnetization effects in interior permanent-magnet synchronous motor," IEEE Trans. Ind. Appl., vol. 39, no. 9, pp. 1264-1271, Sept./Oct. 2003

[7] E. M. Rashad, "Stability Limits of Saturated Interior Permanent Magnet Motors," in conf. Power Electronics and Drives Systems, Kuala Lumpur, 2005, pp. 584 - 589.

[8] Thierry Lubin, Hubert Razik, and Abderrezak Rezzoug, "Magnetic saturation effects on the control of a synchronous reluctance machine," IEEE Trans. Energy Convers. vol. 17, no. 3, pp. 356-362, Sept. 2002.

[9] E.Levi, "Saturation modelling in D-Q axis models of salient pole synchronous machines," IEEE Trans. Energy Convers. vol. 14, no. 1, pp. 44-50, Mar. 1999.

[10] M. Ferrari, N. Bianchi, and E. Fornasiero, "Analysis of rotor saturation in synchronous reluctance and PM-assisted reluctance motors," IEEE Trans. Ind. Appl., vol. 51, no. 1, pp. 169-177, Jan./Feb. 2015.

[11] A. Kilthau and J. M. Pacas, "Parameter-measurement and control of the synchronous reluctance machine including cross saturation," in Conf. Rec. IEEE-IAS Annu. Meeting, Sept.-Oct. 2001, vol. 4, pp. 2302-2309.

[12] Gorazd Stumberger, Bojan Stumberger, and Drago Dolinar "Identification of linear synchronous reluctance motor parameters," IEEE Trans. Ind. Appl., vol. 40, no. 5, pp. 1317-1324, Sept./Oct. 2004

[13] T. Matsuo, T. A. Lipo, "Rotor design optimization of synchronous reluctance machine," IEEE Trans. Energy Convers. vol. 9, no. 2, pp. 1317-1324, Sept./Oct. 2004.

\section{AUTHORS’ INFORMATION}

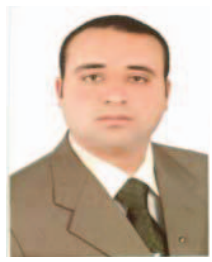

Mohamed N. Ibrahim was born in Kafrelshiekh, Egypt on September 18, 1986. He has graduated from Faculty of Engineering, Kafrelshiekh University, Egypt on 2008. He received his MSc. degree in Electrical Power and Machines Engineering from Tanta University in 2012. Since 2012, he is working as an assistant lecturer at the Department of Electrica Engineering, Faculty of Engineering, Kafrelshiekh

University, Egypt

$\mathrm{He}$ is currently working towards the $\mathrm{PhD}$ at Ghent University, Belgium in cooperation with Tanta University, Egypt. His research interests are in Electrical Machines, Electrical Drives, Power Electronics and Renewable Energy Systems

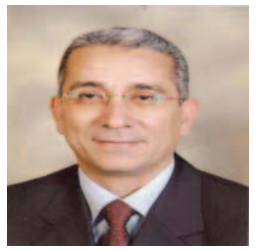

Prof. Essam M. Rashad was born in Shebin ElKom, Egypt in 1960. He received his BSc degree from the department of Electric Power and Machines Engineering., Faculty of Engineering, Shebin El-Kom, Menoufiya University, Egypt in May 1983. In 1987 and 1992 he received MSc and $\mathrm{PhD}$, respectively both from faculty of Engineering Alexandria university, Egypt. From 1985 to 1990, he was an offshore electrical engineer in Belayim Petraulem Company, Egypt. In 1992 he has joined Faculty of Engineering, Tanta University, Egypt, where he is currently a Professor and Head of Electrical Power and Machines Engineering. From Feb. to Aug 2000, he was a visiting researcher in Faculty of Engineering, Nagasaki University, Japan. In summer 2003, he was a visiting researcher at Faculty of Engineering and Applied Science, Memorial University of Newfoundland, St. John's, NL, Canada. From 2004 to 2009, he was Head of Electrical Technology Department, Buraydah College of Technology, Kingdom of Saudi Arabia From 2011 to 2014, he was Vice Dean for Education and Student affairs of Faculty of Engineering, Tanta University, Egypt.

Prof. Rashad research interests include electrical machine analysis and design, electrical drives, power electronics and renewable energy systems.

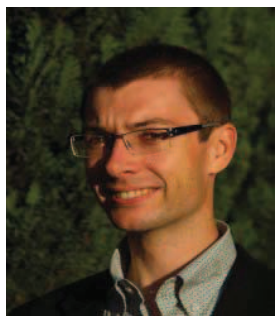

Peter Sergeant received the M.Sc. degree in electromechanical engineering in 2001, and the $\mathrm{Ph} . \mathrm{D}$. degree in engineering sciences in 2006 , both from Ghent University, Ghent, Belgium. In 2001, he became a researcher at the Electrical Energy Laboratory of Ghent University. He became a postdoctoral researcher at Ghent University in 2006 (postdoctoral fellow of the Research Foundation - Flanders) and at Ghent University College in 2008. Since 2012, he is associate professor at Ghent University. His current research interest include numerical methods in combination with optimization techniques to design nonlinear electromagnetic systems, in particular, electrical machines for sustainable energy applications. 